\title{
Modelling the Adverse Effects Associated With Ecstasy (MDMA) Usage
}

\author{
J.E. Fisk ${ }^{*}, 1$, P.N. Murphy ${ }^{2}$, C. Montgomery ${ }^{3}$ and F. Hadjiefthyvoulou ${ }^{1}$ \\ ${ }^{1}$ School of Psychology, University of Central Lancashire, UK \\ ${ }^{2}$ Dept. of Social \& Psychological Sciences, \& Evidence-based Practice Research Centre, Edge Hill University, UK \\ ${ }^{3}$ School of Psychology, Liverpool John Moores University, UK
}

Keywords: Adverse effects, ecstasy, alcohol.

\section{INTRODUCTION}

Previous studies have shown that users of the street drug ecstasy (MDMA) report that its use is related to adverse effects with regard to mood, and some other psychological and behavioural aspects of their lives [1-3]. However, such findings are potentially subject to distorting influences such as the effects of other drugs used concurrently with ecstasy [4], sleep disturbance [5], and external influences such as media reports of ecstasy related harm which may increase users' propensity to attribute adverse effects to their use of the drug [6]. Statistical analysis of self-reported adverse effects can also be difficult due to distribution problems arising from a large number of zero scores for particular effects [3]. The present study sought to overcome these difficulties in studying the self-reported adverse effects of ecstasy consumption by using negative binomial regression analysis to manage distributional difficulties, and to examine variables with the potential to distort ecstasy users' attributions for such effects.

\section{METHOD}

The sample comprised 159 ecstasy polydrug users $(80$ males) with a mean age of 21.55 years $(S D=2.47$ years $)$. Participants were requested not to use ecstasy for at least 7 days, or any other illegal drug for 24 hours, prior to testing. Participants' drug using history was obtained by a background questionnaire. Self-report ratings were obtained for each of 15 items comprising a scale previously reported [2-3], reflecting mood or other psychological variables (e.g. 'Sad', 'Confused'). Participants rated each item with regard to changes since initiation of ecstasy use on a five point scale ('much more', 'more', no change', 'less', and 'much less'). Other measures recorded concern over ecstasy related dangers $(0=$ extremely concerned, $4=$ not concerned $)$, and awareness of ecstasy related harms $(0=$ very aware, $4=$ not aware). Measures of sleep quality were obtained from the Epworth Sleepiness Scale [7], and measures of depression, and anxiety from a mood adjective checklist [8].

*Address correspondence to this author at the School of Psychology, University of Central Lancashire, UK; Tel: 44 (0) 1772 894465; Fax: 44 (0) 1772 892925; E-mail: JFisk@UCLAN.AC.UK

\section{RESULTS}

Using the total number of adverse effects reported as the dependent variable, significant relationships were found for weeks since last ecstasy use and estimated lifetime ecstasy consumption, these relationships being negative and positive, respectively. Weeks since first ecstasy use and the frequency of its use per week were not related to the total number of adverse effects reported. Additionally, the dependent variable was positively related to the frequency of concurrent alcohol and ecstasy use, daytime sleepiness (i.e. poor sleep quality), anxiety, and level of concern about the adverse effects of ecstasy use. Self ratings of general health were negatively related to the dependent variable. Significant relationships were not found with the number of precautions taken when ecstasy was used, awareness that ecstasy use may have harmful effects, depression, or the concurrent use with ecstasy of amphetamine, cannabis, or cocaine.

\section{CONCLUSIONS}

The results show that the total number of self-reported adverse effects attributed to the use of ecstasy is positively related to lifetime consumption, but inversely related to duration of abstinence from the drug. This latter effect could reflect the return of some neuronal functions to a pre-ecstasy use level [9-10]. Overall duration and frequency of use do not appear to be related to the level of adverse effects reported. The lack of relationship between awareness of ecstasy's effects and the total of adverse effects reported does not support the assertion that users' reports of such effects may be magnified in any substantial way by media and other influences [6]. The concurrent use of alcohol, rather than cannabis, with ecstasy may be an important area for future research [4].

\section{REFERENCES}

[1] Parrott AC, Buchanan T, Scholey AB, Heffernan T, Ling J, Rodgers, J. Ecstasy/MDMA attributed problems reported by novice, moderate, and heavy users. Hum Psychopharmacol 2002; 17: $309-12$.

[2] Murphy PN, Wareing M, Fisk JE. Users' perceptions of the risks and effects of taking MDMA (Ecstasy). J Psychopharmacol 2006; 20: 447-55.

[3] Fisk JE, Montgomery C, Murphy PN. The association between the negative effects attributed to ecstasy use and measures of cognition and mood among users. Exp Clin Psychopharmacol 2009; 17: 32636. 
[4] Fisk JE, Montgomery C, Wareing M, Murphy PN. The effects of concurrent cannabis use among ecstasy users: neuroprotective or neurotoxic. Hum Psychopharmacol 2006; 21: 355-66.

[5] Montgomery C, Fisk JE, Wareing M, Murphy PN. Self-reported sleep quality and cognitive performance in ecstasy users. Hum Psychopharmacol 2007; 22: 537-48.

[6] Cole JC, Michailidou K, Jerome L, Sumnall HR. The effects of stereotype threat on cognitive function in ecstasy users. J Psychopharmacol 2006; 20: 518-25.

[7] Johns MW. Reliability and factor-analysis of the Epworth Sleepiness Scale. Sleep 1992; 15: 376-81.
$[8$

Fisk JE, Warr P. Age-related impairment in associative learning: the role of anxiety, arousal and learning self-efficacy. Pers Individ Dif 1996; 21: 675-86.

[9] Buchert R, Thomasius R, Wilke F, et al. A voxel-based PET investigation of the long-term effects of "ecstasy" consumption on brain serotonin transporters. Am J Psychiatry 2004; 161: 1181-9.

[10] Selvaraj S, Hoshi R, Bhagwager Z, et al. Brain serotonin transporter binding in former users of MDMA ('ecstasy'). Br J Psychiatry 2009; 194: 355-9.

(C) Fisk et al.; Licensee Bentham Open.

This is an open access article licensed under the terms of the Creative Commons Attribution Non-Commercial License (http://creativecommons.org/licenses/ by-nc/3.0/) which permits unrestricted, non-commercial use, distribution and reproduction in any medium, provided the work is properly cited. 